\title{
Analysis of benzyldimethyldodecylammonium bromide in chemical disinfectants by liquid chromatography and capillary electrophoresis
}

\author{
Xiaojing Ding ${ }^{\mathrm{a}, *}$, Shifen Mou ${ }^{\mathrm{b}}$, Shan Zhao ${ }^{\mathrm{a}}$ \\ a Beijing Center for Disease Prevention and Control, Dongcheng District, No. 16, He Pingli Zhongjie, Beijing 100013, China \\ ${ }^{\mathrm{b}}$ Research Center for Eco-environmental Sciences, Chinese Academy of Sciences, P.O. Box 2871, Beijing 100085, China
}

\begin{abstract}
Two novel analytical methodologies using capillary electrophoresis (CE) and high-performance liquid chromatography (HPLC) were developed and compared for the determination of benzyldimethyldodecylammonium bromide (BAB) in commercial compound chemical disinfectants. The LC analysis was performed with a Kromasil $\mathrm{C}_{18}(200 \mathrm{~mm} \times 4.6 \mathrm{~mm}, 5 \mu \mathrm{m})$ column and a mobile phase of A:B = 80:20 (A: acetonitrile, B: $4 \mathrm{mmol} / \mathrm{L}$ octanesulfonic sodium- $0.02 \mathrm{~mol} / \mathrm{L}$ acetic sodium, adjusted with acetic acid to $\mathrm{pH} 5.2)$ at a flow rate of $1.0 \mathrm{~mL} / \mathrm{min}$. Detection was by ultraviolet absorption at $262 \mathrm{~nm}$. The CE analysis was performed in a bare fused-silica capillary with $75 \mu \mathrm{m}$ i.d. and total length of $46.4 \mathrm{~cm}$ with a buffer solution of $50 \%$ acetonitrile $-50 \mathrm{mmol} / \mathrm{L} \mathrm{NaH} \mathrm{PO}_{4}, \mathrm{pH} 2.24$. The applied voltage was $20 \mathrm{kV}$. Detection was by ultraviolet absorption at $214 \mathrm{~nm}$. Under optimized conditions, the HPLC retention time and CE migration time for BAB was 9.18 and $5.08 \mathrm{~min}$, respectively. Calibration curves of peak area versus concentration gave correlation coefficients of 0.9996 for HPLC and 0.9994 for CE. The detection limits for HPLC and CE were $1.6 \mathrm{mg} / \mathrm{L}$ and $0.2 \mathrm{mg} / \mathrm{L}$, respectively. Average recoveries at three concentration levels $(50,100,200 \mathrm{mg} / \mathrm{L}$ for HPLC; $20,40,100 \mathrm{mg} / \mathrm{L}$ for CE) were $99.94 \pm 1.5,99.64 \pm 1.3$ and $99.61 \pm 0.4 \%$ for HPLC and $120.47 \pm 2.6$, $102.06 \pm 8.7$ and $103.05 \pm 3.0 \%$ for $\mathrm{CE}$, respectively. Although both methods were shown to be suitable for the determination of BAB in commercial disinfectant compounds, CE provided analysis with less solvent purchase/disposal and better column efficiency, whereas HPLC provided superior precision.
\end{abstract}

(C) 2004 Elsevier B.V. All rights reserved.

Keywords: Disinfectants; Benzyldimethyldodecylammonium bromide; Benzalkonium bromide; Quaternary ammonium compounds; Surfactants

\section{Introduction}

Benzyldimethyldodecylammonium bromide is the chemical name of benzalkonium bromide (BAB). It is a lowefficacy disinfectant and most effective against bacteria in migrule form and lipophilic virus [1]. It has been widely used in compound chemical disinfectants due to its low price since its introduction in 1953. In China, BAB, though neurotoxic, is more preferred than benzalkonium chloride (BAC or BAK, $\mathrm{BzCl}$ ) - another popular disinfectant in Germany, USA, UK etc. Much attention should be paid to the fact that BAC in all the reported references is a mixture of alkylbenzyldimethylammonium chlorides, which differ only in the length of the alkyl side chain $\left(\mathrm{C}_{8}-\mathrm{C}_{18}\right)$ [9-28], whereas $\mathrm{BAB}$ is a single component $-\mathrm{C}_{12}-\mathrm{BAB}$ [1]. $\mathrm{BAB}$ 's combination with certain high-efficacy disinfectant, such

\footnotetext{
* Corresponding author. Fax: +86-10-64214405.

E-mail address: dxj_wry@yahoo.com (X. Ding).
}

as glutaraldehyde can enhance the disinfecting efficacy of compound disinfectant considerably. If the concentration of $\mathrm{BAB}$ in compound chemical disinfectants is lower than the manufacturer's specification, the compound chemical disinfectant will not effectively kills bacteria and virus. However, if the concentration of $\mathrm{BAB}$ in compound chemical disinfectants is higher than the permission level, there will be toxicity to humans. For sake of safety, the Ministry of Public Health of China has set safety level for BAB at $0.2 \%$ for the disinfection of skin and hands. Instrumental methods are recommended the first choice for the assay of BAB [2]. Therefore, instrumental methods with rapidity and simplicity for the assay of BAB in compound chemical disinfectants are required for product quality control.

At present, methods for the assay of BAB in disinfectant compound are mainly sodium tetraphenylborate titration [3], UV spectrophotometry [4,5] and artificial neural network [6]. No high-performance liquid chromatography (HPLC) or capillary electrophoresis (CE) method for its assay has 
been reported. However, methods, such as difference spectrophotometry [7], immunoassay [8], flow injection ionspray mass spectrometry mass spectrometry [9], HPLC and $\mathrm{CE}$ for the analysis of BAC, with similar structure as that of BAB, have been reported. HPLC [10-14] and CE [15-28] are the most frequently used methods for routine determination of BAC in ophthalmic solutions [10-13,28], nasal drug solution $[19,20]$, common household cleaner disinfectant [25], lozenges [18] and effluent from hospitals [14], etc. Prince [21] compared the analysis of BAC using HPLC to analysis using HPCE. No real samples were analyzed. All the above-mentioned HPLC methods separated the BAC homologs generally used columns with cyano $[10,13,21]$, cyano-amido [14], phenyl [11], ODS-2 [20] and RP-C 8 stationary phase $[12,17]$. The separation of BAC homologs on the commonly used $\mathrm{C}_{18}$ stationary phase has not been reported.

$\mathrm{CE}$ is especially suited for the determination of charged species. The successful use of CE for BAC homologues determinations has proven that it can serve as a routine technique in many real-world applications [15-20,23,25-27]. Since samples with different matrices may require different chromatographic conditions and the $\mathrm{C}_{12}-\mathrm{BAB}$ was more concerned in present study. There is no need to resolve the homologues. HPLC or CE methods for the analysis of BAC must be modified accordingly for precise determination of $\mathrm{BAB}$ in compound chemical disinfectant.

The aim of this study is: (i) to develop a HPLC method for the analysis of $\mathrm{BAB}$ in compound chemical disinfectant on a $\mathrm{C}_{18}$ stationary phase, (ii) to establish a $\mathrm{CE}$ method to routinely determine $\mathrm{BAB}$ in compound chemical disinfectant, and to compare the results by using the established HPLC method. The influences of CE separation conditions (i.e. organic modifier content, buffer concentration, $\mathrm{pH}$ and rinsing conditions between runs etc.) were investigated in detail.

\section{Experimental}

\subsection{Chemicals and reagents}

The water for the preparation of all solutions was made by a Millipore Milli-QRG ultra-pure water system (Bedford, MA, USA). HPLC-grade acetonitrile was purchased from Fisher Scientific (Fair Lawn, NJ, USA). All chemicals were of analytical grade or higher purity unless otherwise stated.

1-Octanesulfonic sodium (98\%, Sigma, St. Louis, MO, USA); BAB was supplied by Kangsheng Da Scientific and Trade Co. (Beijing, China). The stock solutions (100 mg/L) for HPLC and CE analyses were prepared separately by dissolving $100 \mathrm{mg}$ BAB in $100 \mathrm{~mL}$ water and CE buffer, respectively. The stock solution for HPLC was stored in a polyethylene bottle at $4{ }^{\circ} \mathrm{C}$. The working solutions $(50,100$, $150,200,250,300 \mathrm{mg} / \mathrm{L}$ ) were prepared by serial dilution of the stock solution with water. The stock solution for CE was stored in volumetric flask at $4{ }^{\circ} \mathrm{C}$. The working solutions (20,
$40,60,80,100,150 \mathrm{mg} / \mathrm{L}$ ) were prepared by serial dilution of the stock solution with CE buffer.

\subsection{Apparatus}

(a) HPLC system-A Waters 2690-996 high-performance liquid chromatography (Milford, MA, USA) equipped with a 600 gradient pump was employed together with a Waters Millennium 2010 Chromatography Manager workstation (version 2.15) for instrument control as well as data acquisition and processing.

(b) HPLC conditions - an analytical column of Kromasil $\mathrm{C}_{18}(200 \mathrm{~mm} \times 4.6 \mathrm{~mm}, 5 \mu \mathrm{m})$ was used with a mobile phase of $\mathrm{A}: \mathrm{B}=80: 20$ (A: acetonitrile, $\mathrm{B}: 4 \mathrm{mmol} / \mathrm{L}$ octanesulfonic sodium $-0.02 \mathrm{~mol} / \mathrm{L}$ acetic sodium, adjusted with acetic acid to $\mathrm{pH} 5.2$ ) at a flow rate of $1.0 \mathrm{~mL} / \mathrm{min}$. A Waters 996 photodiode array detector was used and the detection wavelength was set at $262 \mathrm{~nm}$. All analyses were conducted under isocratic conditions at room temperature. The injection volume of standard and sample solutions was $10 \mu \mathrm{L}$ by a Waters 717 plus autosampler. In this study, the peak area measurements for all calculations were adopted.

(c) CE system-A P/ACE system 5000 (Beckman Instruments, Fullerton, CA, USA) electrophoresis apparatus equipped with both UV and diode array detector was controlled by a Pentium/100 MHz personal computer. All the data was collected and analyzed using the System Gold software.

(d) Capillary column - a bare fused-silica capillary (Yongnian Ruifeng Sepu Peijian plant, HeBei Province, China) with $75 \mu \mathrm{m}$ i.d. and total length of $46.4 \mathrm{~cm}$ was used. The capillary column, when new, was flushed successively with $1 \mathrm{~mol} / \mathrm{L} \mathrm{NaOH}$ for $30 \mathrm{~min}$, pure water for $5 \mathrm{~min}, 1 \mathrm{~mol} / \mathrm{L} \mathrm{HCl}$ for $3 \mathrm{~min}$ and finally pure water for $5 \mathrm{~min}$. Before use, the capillary was flushed with $0.1 \mathrm{~mol} / \mathrm{L} \mathrm{NaOH}$ for $5 \mathrm{~min}$, water for $5 \mathrm{~min}$ and running electrolyte buffer for $15 \mathrm{~min}$. Then, samples were introduced onto the capillary via electrokinetic injection by applying $\mathrm{N}_{2}$ pressure $(0.5 \mathrm{MPa})$ for $3 \mathrm{~s}$. A constant voltage of $20 \mathrm{kV}$ was used (current of ca $19.4 \mu \mathrm{A}$ ) for all experiments. Between runs, the capillary was rinsed with electrolyte solution for $3 \mathrm{~min}$. The running electrolyte buffer in both inlet vial and outlet vial must be renewed after six series of injections. The data from the first runs should be discarded till high injection repeatability in terms of migration time and peak area was obtained. All electrophoresis runs were performed at temperature $25^{\circ} \mathrm{C}$. Detection was set at $214 \mathrm{~nm}$ by a fixed-wavelength detector.

(e) $\mathrm{CE}$ buffer-(1) $3.9002 \mathrm{~g}$ of $\mathrm{NaH}_{2} \mathrm{PO}_{4} \cdot 2 \mathrm{H}_{2} \mathrm{O}$ was weighed into a $250 \mathrm{~mL}$ volumetric flask. $100 \mathrm{~mL}$ of water was added to dissolve the salt and then dilute to volume, $100 \mathrm{mmol} / \mathrm{L}$ of $\mathrm{NaH}_{2} \mathrm{PO}_{4}$ was obtained. (2) A $1.7 \mathrm{~mL}$ concentrated phosphoric acid $(85 \%)$ was diluted to $250 \mathrm{~mL}$ with water. The final concentration 
of phosphoric acid is $100 \mathrm{mmol} / \mathrm{L}$. (3) A $46 \mathrm{~mL}$ of $100 \mathrm{mmol} / \mathrm{L}$ phosphoric acid, $4 \mathrm{~mL}$ of $100 \mathrm{mmol} / \mathrm{L}$ $\mathrm{NaH}_{2} \mathrm{PO}_{4}$ and $50 \mathrm{~mL}$ of acetonitrile were added to a $100 \mathrm{~mL}$ glass measuring cylinder with a lid. A buffer solution of $50 \%$ acetonitrile- $50 \mathrm{mmol} / \mathrm{L} \mathrm{NaH} \mathrm{PO}_{4}$ of $\mathrm{pH} 2.24$ was obtained.

(f) $\mathrm{pH}$ meter-Model JC-402 $\mathrm{pH} / \mathrm{mV}$ (Beijing Chuangye Instrumental Plant, Beijing, China).

\subsection{Preparation of compound chemical disinfectant samples}

Samples for HPLC analysis were simply diluted 1:50 with water and then filtered through $0.45 \mu \mathrm{m}$ hydrophilic filters before analysis. Samples for CE analysis were diluted 1:100 with $\mathrm{CE}$ buffer and then filtered through $0.45 \mu \mathrm{m}$ hydrophobic filters before analysis.

\section{Results and discussion}

\subsection{Choice of detection wavelength}

UV detection has reasonably been the first choice in both HPLC and CE analysis. Fig. 1 illustrates the scan diagram of diode array detection of BAB in HPLC mobile phase. For HPLC analysis, the detection wavelength at $262 \mathrm{~nm}$ was selected where the background absorbance of mobile phase was low. However, considering the sensitivity of CE analysis, the detection wavelength at $214 \mathrm{~nm}$ was selected and a good peak shape of BAB was obtained.

\subsection{HPLC method development}

\subsubsection{Choice of chromatographic separation conditions}

The same ionic characteristics that make BAB suitable for $\mathrm{CE}$ analysis make it troublesome for the commonly used reversed-phase bonded HPLC analysis, if certain conditions are not used. In reversed-phase bonded HPLC, BAB

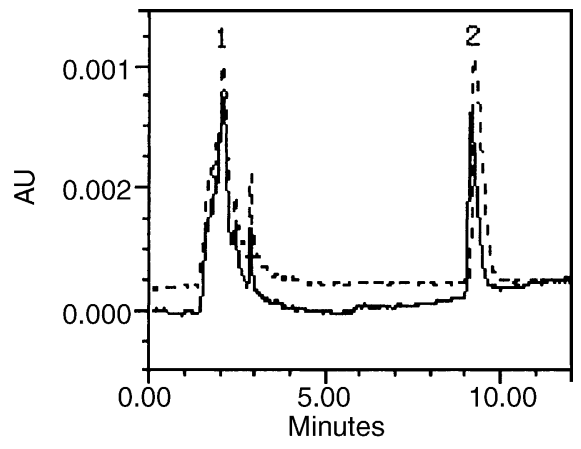

Fig. 2. Chromatograms of sample $1^{\#}$ diluted 1:50 with water (solid line) and sample $1^{\#}$ spiked with $50 \mathrm{mg} / \mathrm{L}$ benzalkonium bromide after diluted 1:50 with water (dotted line). Peaks: (1) unknown and (2) BAB.

in cationic form is not retained by $\mathrm{C}_{18}$ stationary phase and an ion-pair agent must be added to form neutral ion-pairs to be retained by the $\mathrm{C}_{18}$ stationary phase. To further improve the retention behavior of the ion-pairs, inorganic salt was also added to produce a salting-out effect. In addition, the $\mathrm{pH}$ of the mobile phase must be adjusted to get better peak shapes. The experiment showed that octanesulfonic sodium and sodium acetate were a suitable ion-pair agent and inorganic salt, respectively. The optimum concentration for $\mathrm{ACN}, \mathrm{NaAC}$ and octanesulfonic sodium were $80 \%$, $0.02 \mathrm{~mol} / \mathrm{L}$ ( $\mathrm{pH}$ was adjusted with acetic acid to 5.2 ) and $4 \mathrm{mmol} / \mathrm{L}$. Fig. 2 illustrated the chromatogrms of sample $1^{\#}$ diluted 1:50 with water (solid line) and sample $1^{\#}$ spiked with $50 \mathrm{mg} / \mathrm{L}$ BAB after diluted 1:50 with water (dotted line) under the optimized chromatographic conditions. The BAB peak could be clearly separated from the unknown peaks in the real samples.

\subsubsection{Detection limit, precision and linear range}

Under the optimized chromatographic conditions, the peak area $(A)$ and the concentration $(C, \mathrm{mg} / \mathrm{L})$ of $\mathrm{BAB}$ had good linear relationships. The regression equation was $A=404 C-2030$ with a correlation coefficient $r=0.9996$. The linear range was from 20 to $400 \mathrm{mg} / \mathrm{L}$. The detection

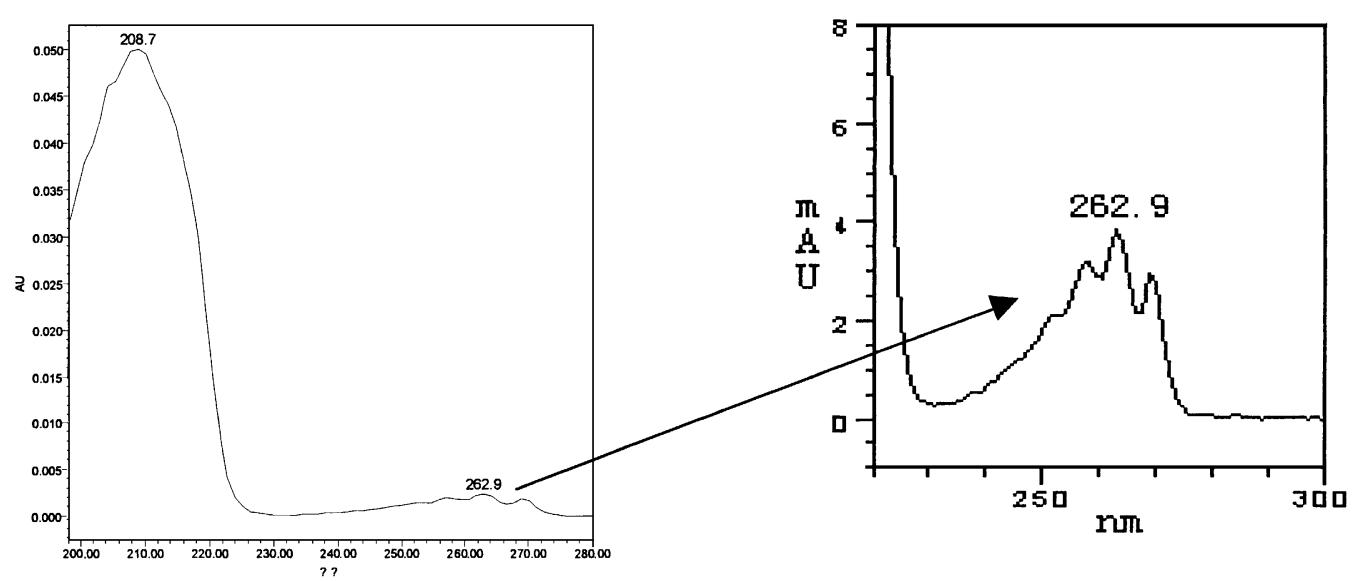

Fig. 1. The ultraviolet absorption spectra of BAB in the optimized chromatographic mobile phase (see (b) in Section 2.2) through on-line scan by diode array detector. 
limit $(\mathrm{S} / \mathrm{N}=3)$ was $1.6 \mathrm{mg} / \mathrm{L}$. The precision was evaluated by performing nine replicate analysis of a standard concentration of $60 \mathrm{mg} / \mathrm{L}$. The relative standard deviations for retention time and peak area were 0.6 and $1.6 \%$, respectively.

\subsubsection{Real sample analysis}

Three samples were diluted with pure water and determined in triplicates after filtered through a $0.45 \mu \mathrm{m}$ filter membrane. The results were $0.62,0.63$ and $0.63 \%(w / v)$, respectively. Spike studies were performed by sample $1^{\#}$. Three concentration levels of BAB were added (50, 100, $200 \mathrm{mg} / \mathrm{L}$ ) after its dilution 1:100 with pure water. Average recoveries $(n=3)$ with R.S.D. values were $99.94 \pm 1.5$, $99.64 \pm 1.3$ and $99.61 \pm 0.4 \%$, respectively. Much attention should be paid that several drops of methanol must be added to eliminate the foaming formed in the process of dilution.

\subsection{CE method development}

\subsubsection{Selection of background electrolyte}

The ionic character of BAB makes it a suitable molecule for $\mathrm{CE}$ analysis. Unfortunately, the analysis of BAC has been proven to be problematical because of their ability to adsorb strongly onto the capillary wall and to form micelles at very low concentrations, leading to peak loss/tailing and thus, poor resolution, irreproducible migration time and low detection sensitivity [22,24]. However, the addition of organic solvents such as methanol, acetonitrile(ACN) $[17,18,21,24,25-28]$ and tetrahydrofuran (THF) [16] in the CE buffer system and/or sample solution to disrupt micelle formation and/or to reduce the strongly adsorption onto the capillary surfaces has been proven to be quite effective. Methanol has been proven to produce a strong baseline noise and it was not recommended to add this solvent into CE buffer. THF was usually used as buffer additive for more complex samples due to its effective separation ability. ACN was found to show a sufficient peak resolution with short migration times, so it was usually applied for the analysis of samples with simple composition [17]. Since only $\mathrm{C}_{12}-\mathrm{BAB}$ was of interest in this study, therefore, $\mathrm{ACN}$ was used as buffer additive. Keep the $\mathrm{pH}$ of buffer and $50 \mathrm{mmol} / \mathrm{L} \mathrm{NaH}_{2} \mathrm{PO}_{4}$ unchanged, the migration time of $\mathrm{BAB}$ decreased with the increase in $\mathrm{ACN}$ concentration from 25 to $70 \%$ (v/v). However, the separation between $\mathrm{BAB}$ and the unknown peak became poor. So, $50 \%$ was selected as the ACN optimum concentration.

It was also found that increasing the concentration of $\mathrm{NaH}_{2} \mathrm{PO}_{4}$ can minimize the adsorption of BAB to the silica capillary wall, and the peak shape of $\mathrm{BAB}$ was thus improved. The optimum concentration of $\mathrm{NaH}_{2} \mathrm{PO}_{4}$ was $50 \mathrm{mmol} / \mathrm{L}$.

The use of buffers with low $\mathrm{pH}(<5)$ can reduce the dissociation of the silanol groups on the capillary surface, and

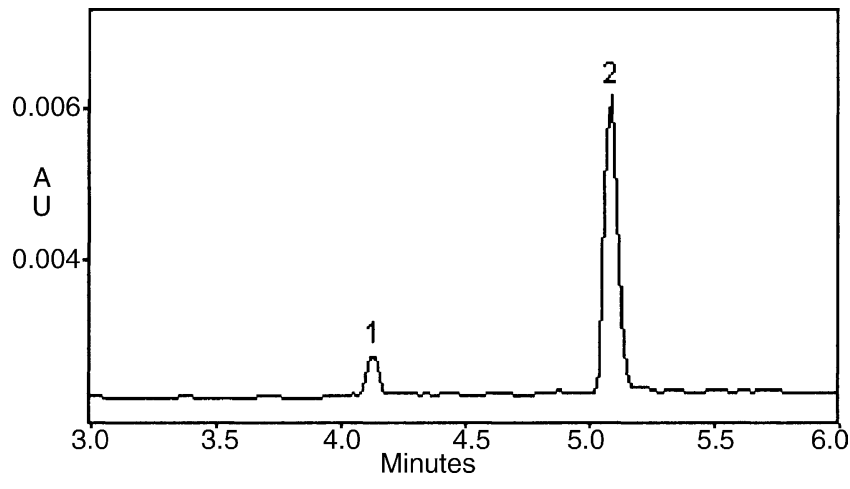

Fig. 3. Electropherogram of benzalkonium bromide in sample $1^{\#}$ diluted 1:100 with buffer. Capillary conditions are shown in Section 2.2. (1) Unknown and (2) BAB.

thus the adsorption of BAC was decreased [22]. The peak areas of BAC have been proven increased when the buffer $\mathrm{pH}$ decreased.

The buffer $\mathrm{pH}$ values ranged from 3.0 to 5.0 have been used for the analysis of BAC. Some extreme $\mathrm{pH}$ values such as 2.3 [28] and 2.0 [19] have also been reported to overcome the problem of adsorption of BACs on the capillary wall. In this study, $\mathrm{pH} 2.24$ was finally selected. With the exposure time of the buffer to the high-pressure field increased, buffer depletion occurred, and thus influenced the migration behavior of BAB. The peak area of BAB decreased with increased number of injections. Therefore, it is recommended to determine the maximum number of injections that can be performed using a single pair of run buffer vials without significant depletion effects [29]. The complete renewal of buffer solutions after six injections could avoid this phenomenon. Both the precision of migration time and that of peak area were improved.

The correct choice of preconditioning steps before each run is prerequisite for the reproducibility of quantitative analysis. It has been tested that the re-equilibration time needed can be reduced to a minimum, if great $\mathrm{pH}$ differences between washing and re-equilibration solutions are avoided [29]. Since the $\mathrm{pH}$ value of buffer in the present study is 2.24 , the wash step with $0.1 \mathrm{~mol} / \mathrm{L} \mathrm{NaOH}$ could be omitted in consideration of saving time. The capillary was washed only with buffer between runs, and thus both the precision of migration time and that of peak area were improved. Fig. 3 illustrates the electropherogram of benzalkonium bromide in sample $1^{\#}$ diluted 1:100 with buffer. The BAB peak could be clearly separated from the unknown peaks in the real samples in a shorter analysis time compared with HPLC.

\subsubsection{Linear range, detection limit and precision}

Under the optimized CZE conditions, the linearity of the method was studied in the range from 20 to $400 \mathrm{mg} / \mathrm{L}$ using external standard calibration. The peak area $(A)$ and the concentration $(C, \mathrm{mg} / \mathrm{L})$ of $\mathrm{BAB}$ had good linear relationships. The regression equation was $A=2.3 \times 10^{2} \mathrm{C}-58$ with a correlation coefficient $r=0.9994$. The detection limit 
$(\mathrm{S} / \mathrm{N}=3)$ was $0.2 \mathrm{mg} / \mathrm{L}$. The repeatability of the method was tested using 10 replicate injections of a standard solution. The R.S.D. of the migration time was $0.62 \%$. The R.S.D. of the peak area was $3.3 \%$.

\subsubsection{Real sample analysis}

The same samples as that used in HPLC determination were diluted with $\mathrm{CE}$ buffer and determined in triplicates, respectively. The results were $0.64,0.62$ and $0.63 \%(w / v)$ respectively and agreed well with the result of HPLC determination. Both results agreed well with the specified amount $(0.6 \%)$. Average recoveries at three concentration levels (20, $40,100 \mathrm{mg} / \mathrm{L}$ ) were $120.47 \pm 2.6,102.06 \pm 8.7$ and $103.05 \pm$ $3.0 \%$, respectively.

Since the analyzed samples contained only $\mathrm{C}_{12}$-BAB due to its greater disinfecting ability as the manufacturer's declaration, it was expected that no peaks other than $\mathrm{C}_{12}$ was observed in both the chromatogram and the electropherogram besides the matrix peaks assigned to peak 1 as Figs. 2 and 3 illustrated, respectively. However, when a BAC sample containing $\mathrm{C}_{12}, \mathrm{C}_{14}$ and $\mathrm{C}_{16}$ was injected, three peaks in order of increasing alkyl chain length were detected accordingly under both HPLC and CE separation conditions. Both HPLC system and CE system equipped with diode array detector further confirm the peak purity. Since the HPLC column efficiency is lower than the efficiency of CZE, $\mathrm{C}_{12}$ was baseline separated from $\mathrm{C}_{14}$ and $\mathrm{C}_{16}$ but the separation between $\mathrm{C}_{14}$ and $\mathrm{C}_{16}$ was poor under HPLC conditions. $\mathrm{C}_{12}, \mathrm{C}_{14}$ and $\mathrm{C}_{16}$ could be well separated under optimized $\mathrm{CE}$ conditions. There were no interferences from the higher and lower homologs to $\mathrm{C}_{12}$ as well as other components in the compound chemical disinfectant under optimized both HPLC and CZE conditions. The simultaneous determination of $\mathrm{C}_{12}, \mathrm{C}_{14}, \mathrm{C}_{16}$ and $\mathrm{C}_{18}$ in real samples by both HPLC and $\mathrm{CE}$ method is currently in progress in our laboratory.

Much attention should be paid that the capacity of a capillary is small. With the running numbers of real samples increased, the capillary wall would adsorb the matrices in real samples and the adsorption was usually irreversible. Therefore the capillary must be discarded after the analysis of about 40 samples.

\section{References}

[1] X. Guangbo, Sterilization, Disinfection, Antisepsis, Preservation, People's Health Press, Beijing, 1993, p. 283.

[2] Technical Standards for Disinfection, The Ministry of Public Health, Beijing, 2002.

[3] Chinese Pharmacopoeia, second ed., Chemical Industry Press, Beijing, 2000, p. 361.

[4] Y. Wenchu, Chin. J. Phys. Chem. Test Chem. Div. 32 (4) (1996) 222.

[5] F. Yonglan, Chin. J. Anal. Chem. 26 (10) (1998) 1209.

[6] Z. Yan, X. Jiang, Z. Wang, Chin. J. Mod. Appl. Pharm. 17 (2) (2000) 132.

[7] K. Kovacs-Hadady, I. Fabian, J. Pharm. Biomed. Anal. 16 (1998) 733.

[8] J.P. Bull, A.N. Serreqi, T. Chen, C. Breuil, Water Res. 32 (12) (1998) 3621.

[9] S. Kawakami, R.H. Callicott, N. Zhang, Analyst 123 (1998) 489.

[10] A. Gomez-Gomar, M.M. Gonzalez-Aubert, J. Garces-Torrents, J. Costa-Segarra, J. Pharm. Biomed. Anal. 8 (1990) 871.

[11] R. Brent Milier, C. Chen, C.H. Sherwood, J. Liq. Chromatogr. 16 (1993) 3801.

[12] G. Santoni, A. Medica, Farmaco 49 (1994) 751.

[13] G. Parhizkari, G. Delker, R.B. Miller, C. Chen, Chromatographia 40 (1995) 155

[14] K. Kummerer, A. Eitel, U. Braun, P. Hubner, F. Daschner, G. Mascart, M. Milandri, F. Reinthaler, J. Verhoef, J. Chromatogr. A 774 (1997) 281.

[15] K.D. Altria, J. Elgey, J.S. Howells, J. Chromatogr. A 686 (1996) 111.

[16] E. Piera, P. Erra, M.R. Infante, J. Chromatogr. A 757 (1997) 275.

[17] K. Heinig, C. Vogt, G. Werner, Fresenius J. Anal. Chem. 358 (1997) 500.

[18] R.B. Taylor, S. Toasaksiri, R.G. Reid, J. Chromatogr. A 798 (1998) 335.

[19] M. Jimidar, I. Beyns, R. Rome, R. Peeters, G. Musch, Biomed. Chromatogr. 12 (1998) 128.

[20] J.L. Bernal, M.J. del Nozal, M.T. Martin, J.C. Diez-Masa, A. Cifuentes, J. Chromatogr. A 823 (1998) 423.

[21] S.J. Prince, H.J. McLaury, L.V. Allen, P. McLaury, J. Pharm. Biomed. Anal. 19 (1999) 877.

[22] K. Heinig, C. Vogt, Electrophoresis 20 (1999) 3311.

[23] J.M. Herrero-Martinez, E.F. Simo-Alfonso, C. Mongay-Fernandez, G. Ramis-Ramos, J. Chromatogr. A 895 (2000) 227.

[24] T.S.K. So, C.W. Huie, J. Chromatogr. A 872 (2000) 269.

[25] W.P. Gardner, J.E. Girard, J. Chem. Educ. 77 (10) (2000) 1335.

[26] A.V. Orjales, M.I.T. Carou, M.C.P. Blanco, P.L. Mahia, M. Lorenzo, D.P. Rodriguez, Chromatographia 51 (2000) 77.

[27] Y. Hou, C. Wu, W. Ding, J. Chromatogr. A 976 (2002) 207.

[28] T.S.K. So, C.W. Huie, Electrophoresis 22 (2001) 2143.

[29] B.X. Mayer, J. Chromatogr. A 907 (2001) 21. 